\title{
LA POÉTICA DE LA AUSENCIA EN COMANCHERÍA (DAVID MACKENZIE, 2016), EL ÚLTIMO WESTERN MODERNO
}

\author{
Javier VOCES FERNÁNDEZ \\ Universidad de Salamanca / Universidad de Cantabria \\ Et exiens vidit multam turbam, \\ et misertus est super eos quia erant \\ sicut oves non habentes pastorem, \\ et coepit docere illos multa.
}

$\operatorname{Marcos} 6,34$

Gracias, maestro

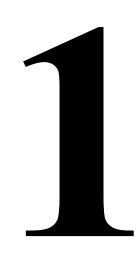

\section{Introducción}

Aludir en pleno siglo XXI al western podría juzgarse como un ejercicio anacrónico. Aún más, plantear un análisis de este género en términos convencionales significaría, a estas alturas, renunciar a todo viso de originalidad. Sin embargo, el western, contra toda lógica histórica, sigue vigente generando todavía hoy nuevas obras cinematográficas de interés extraordinario desde diversas ópticas de análisis.

Quizá, la explicación a esta inmortalidad de un género engendrado por un contexto histórico perfectamente delimitado -el salvaje Oeste, aproximadamente de 1860 a 1890-, haya que buscarla en la magnífica inexactitud que ha generado su definición. Cuando Bazin afirma que el western «es el encuentro entre un medio de expresión y una mitología» (1990:245), hay que entender que esto es así para siempre dado el valor fundacional de la mitología en todas las culturas estudiadas. De este modo, la cultura americana contemporánea seguirá revisando cíclicamente a través de su industria cultural más destacada (la cinematográfica) sus mitos fundacionales. Estos mitos, al igual que los de Hesíodo u Ovidio, cobran fuerza en determinados momentos históricos en los que, debido al estado anímico de la comunidad, ésta necesita reforzar su identidad común y reafirmar así los valores iniciales sobre los que construyó el proyecto original.

Las tensiones generadas por las inercias económicas en las sociedades modernas del siglo XXI han propiciado que el momento actual sea difícilmente definible desde el punto de vista historiográfico. No obstante, una cosa es segura: los libros de historia darán buena cuenta de la última gran crisis económica desde 1929, originada en Estado Unidos y fechada a partir del año 2007, exportada, a su vez, al resto del mundo industrializado con el prosaico nombre de la crisis de las hipotecas «basura». 
En la medida en la que el cine cumple también una función testimonial, se podría establecer desde el origen de la crisis económica hasta nuestros días una filmografía específica; una filmografía de la crisis. La lógica de los géneros cinematográficos situaría a este tipo de películas dentro del llamado cine social. Filmes como La gran apuesta (The Big Short, Adam McKay, 2015), en el que se reflexiona sobre la quiebra del sector inmobiliario en EE. UU. que, por otra parte, fue clave en el origen de la crisis a nivel mundial. El capital (Le capital, Costa-Gavras, 2012), donde se retrata la figura del empleado de banca cínico y sin escrúpulos, capaz de mentir y engañar a sus clientes para lograr sus objetivos. The Company Men (John Wells, 2010), reflejo fiel de la realidad de la llamada clase media norteamericana, golpeada por el paro y el consiguiente cambio de estatus económico, entendido esto como uno de los dramas modernos. Up in the Air (Jason Reitman, 2009), película que deshumaniza los despidos motivados por los recortes de plantilla en las empresas estadounidenses...

Los filmes aludidos son solo una pequeña muestra de que puede rastrearse la última gran crisis económica y social de nuestro tiempo a través del séptimo arte: sus orígenes, los afectados, las reacciones de los poderes políticos y económicos, sus consecuencias y, en resumen, el cambio que supuso para el paradigma social occidental.

Las películas citadas, entre muchas otras, tienen una clara intención social. La denuncia de situaciones injustas a través de la gran pantalla produce un efecto mitigador del dolor colectivo. El

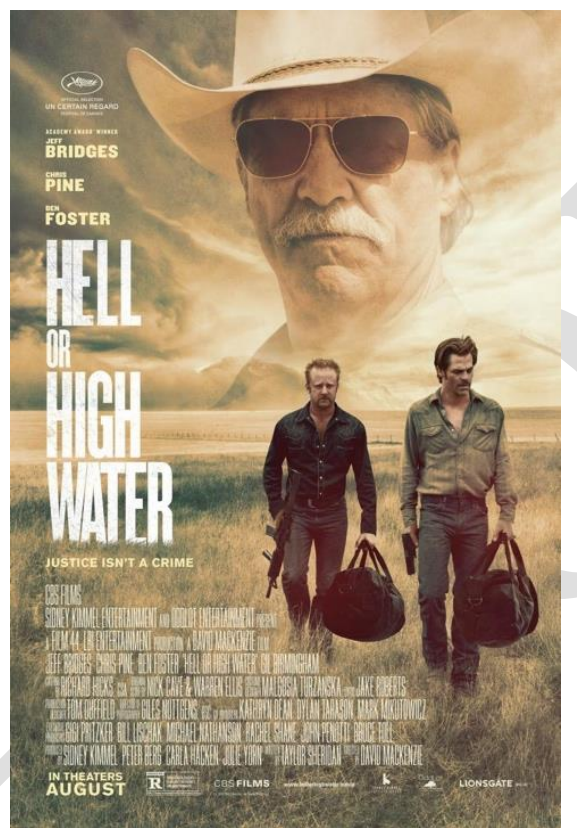

Figura 1: cartel oficial de la película. reconocimiento de las coordenadas espacio temporales (escenarios urbanos en las primeras décadas de los años 2000), y el corte realista de la trama son las características básicas de este tipo de cine. No obstante, hay proyectos cinematográficos que han dado un paso más: Comanchería (Hell or High Water), película dirigida por David MacKenzie en 2016, aborda las consecuencias de la crisis económica apelando a los sentimientos más profundos del ciudadano medio norteamericano, tratando de llegar, así, a su mitología personal. De este modo, la construcción de un western moderno para el tratamiento de este tema sobrepasa con creces las intenciones de un cine social «a secas», para producir un efecto catártico en el espectador. Esta catarsis emana de su identificación con la mitología de una tierra que reconoce como propia; de unos personajes y comportamientos que representan la esencia de su ideal de sociedad.

En Comanchería, ambientada en Texas en la actualidad, Toby (Chris Pine), un joven padre divorciado y su hermano Tanner (Ben Foster), un ex presidiario que acaba de salir de la cárcel, planean una serie de robos a modestas sucursales bancarias. Su objetivo es conseguir el dinero suficiente para salvar la granja familiar que está en peligro de embargo y en la que recientemente se ha descubierto un yacimiento petrolífero. Tras el primer robo, un veterano Ranger de Texas apunto de jubilarse (Jeff Bridges), y su compañero irán tras la pista de los hermanos. 


\section{Relectura perpetua de una mitología}

Como se ha venido afirmando, la fundamentación mitológica de la cultura norteamericana emana del género cinematográfico del western. A diferencia de otras tradiciones culturales, la mitología norteamericana no se transmitió de manera oral para luego fijarse en textos fundacionales, sino que fue filmada. Más aún, como afirma Ángel Fernández-Santos,

Nos encontramos, por consiguiente, ante la formulación de un mito épico o aspirante a tal, sin aparato literario envolvente, un mito nacido ayer o que está naciendo ahora. Estos mitos directos, sin retórica ni lejanía, leyendas surgidas de una prosaica cotidianeidad hostigada por la amenaza de lo excepcional, son los signos básicos del lenguaje del western (2007: 15).

Por tanto, el valor intrínseco del western a diferencia de otras mitologías fundacionales tradicionales (ya se ha citado a Hesíodo y Ovidio), o incluso tradiciones épico-mitológicas (Homero o Virgilio, por referir solo dos ejemplos), es que «la simultaneidad entre el suceso y su conversión en mito era una práctica generalizada en todo el siglo XIX norteamericano» (Fernández-Santos, 2007:16). Este hecho inusual en la tradición cultural implica que cuando Edwin S. Porter filmó Asalto y robo de un tren (The Great Train Robbery) en 1903, estaba siendo testigo de un momento histórico concreto $\mathrm{y}$, al mismo tiempo, sentaba las bases de un género cinematográfico que la sociedad norteamericana adoptaría para siempre como signo identitario. Así, uno tras otro, «el conjunto de filmes resultantes configura un extraordinario cantar de gesta en formato audiovisual, sin precedentes en la historia, sobre la fundación de esta nueva patria» (Balló y Pérez, 2007: 46).

Desde esta perspectiva -más sociológica que fílmica-convendría reforzar la definición clásica de western, evitando apelar únicamente a las expectativas que genera en el espectador y sobrepasando incluso las alusiones a la especialización del contenido narrativo concreto (Sánchez Noriega, 2002), valorando así su origen esencialmente mítico; generador de arquetipos sobre los que se ha construido la sociedad norteamericana actual y con los que (todavía hoy) se siente plenamente identificada. Este hecho está relacionado con la pervivencia y reestructuración constante del western. Más que en cualquier otro género cinematográfico la relación entre el film y el espectador se establece en los mismos códigos históricos y culturales. Pero lo que es más interesante, sin duda, es que los espectadores también comparten con este tipo de películas la esperanza fundacional de la experiencia primera. Es decir, en el western el espectador todavía reconoce el proyecto pionero basado el la idea de refundación social; todavía mantiene vivas las esperanzas que movieron a la conquista del Oeste:

El western hace revivir una y otra vez el instante privilegiado y peligroso en que, sobre un continente nuevo vuelve a comenzar la experiencia primera de los hombres. Es el instante en que se construye la primera cuidad en que se nombra al primer juez y al primer policía, en que Caín debe ser castigado por sus semejantes y no solo por el ojo de Dios (Astre, 1998: 28).

El relato ontológico del género western va mucho más allá de los códigos establecidos. La relación casi ritual entre este tipo de filmes y sus espectadores (especialmente el público norteamericano del sur de EE. UU.), excede la esfera de lo cinematográfico. Lo que Fernández-Santos denomina «la ceremonia de la tragedia» (2007: 9) supone un ejercicio muy complejo de implicaciones 
insospechadas. Tras este tipo de películas se esconde la nostalgia de un tiempo mítico liberado de las múltiples presiones modernas. Un tiempo donde la pulsión violenta bastaba para garantizar una vida sencilla y digna.

La decodificación del filmes como Comanchería, bautizados por la crítica con el nombre de westerns modernos o neowesterns, pasa por la aceptación de la «nostalgia de la barbarie» (Ibídem), un sentimiento que flota en el ambiente opresivo de los estados del sur de EE. UU. y que se resume en la frase pronunciada por uno de los testigos que puede colaborar en la identificación de los hermanos atracadores de bancos: «es ridículo, la época en la que se podían robar bancos, intentar vivir y gastarse el dinero terminó hace mucho. Ya no volverá». Esta afirmación recoge con aires exóticos el anhelo de un tiempo pasado en el que el hombre era libre para forjar su propio destino. Un tiempo salvaje en el que la violencia formalizada se entendía como una manifestación del derecho sagrado de libertad. Un tiempo, en definitiva, en el que se estaba componiendo el «poema de la civilización».

\section{Reescritura o neowestern: Comanchería}

\section{1. Un tiempo de crisis}

Comanchería pertenece a un tiempo suspendido. Una actualidad marcada por la escasez de trabajo, las hipotecas abusivas, los embargos prácticamente inevitables, etc. Es un reflejo fiel de un tiempo poco advertido pero muy real. La acción en el filme se sitúa en algún momento de la actualidad anterior a la llegada de Trump al poder. Este hecho fortuito permite que el espectador consiga una fiel radiografía del americano que le otorgó su confianza en las urnas. Un hombre básico, apegado a la tierra y amante de la violencia por no conocer ninguna otra vía alternativa. Un ciudadano de naturaleza rebelde que se ha resignado en su mayor parte a habitar un tiempo que no reconoce como propio.

Hijos de este tiempo, pues, los hermanos Toby y Tanner se ven abocados a la ilegalidad para hacerse con el dinero que garantizará que nunca llegue a ejecutarse la orden de embargo sobre sus tierras. Es un tiempo complejo que por su devenir ha anulado las soluciones pacíficas. Actuar al margen de la ley, como hacen los protagonistas - los forajidos-, reactiva una cierta esencia mítica que despierta en ellos la conciencia de estar haciendo lo correcto (lo justo), como antes lo hicieron otros.

Por otra parte, Comanchería ofrece una visión muy concreta del sistema bancario que ha de extrapolarse a todo el establishment político y económico norteamericano. Mackenzie retrata una banca en crisis que se aferra con angustia a la letra pequeña de los contratos firmados por los campesinos para ejecutar los posibles embargos de sus propiedades; una banca con muy mala prensa entre los vecinos de las localidades asaltadas ${ }^{1}$.

\footnotetext{
${ }^{1}$ La figura 2 corresponde a un fotograma en el que el espectador puede leer un grafiti hecho en la pared de una sucursal bancaria del Texas Midlands Bank antes de que se produzca un atraco: «Tres incursiones en Irak pero no hay rescate para gente como nosotros».
} 


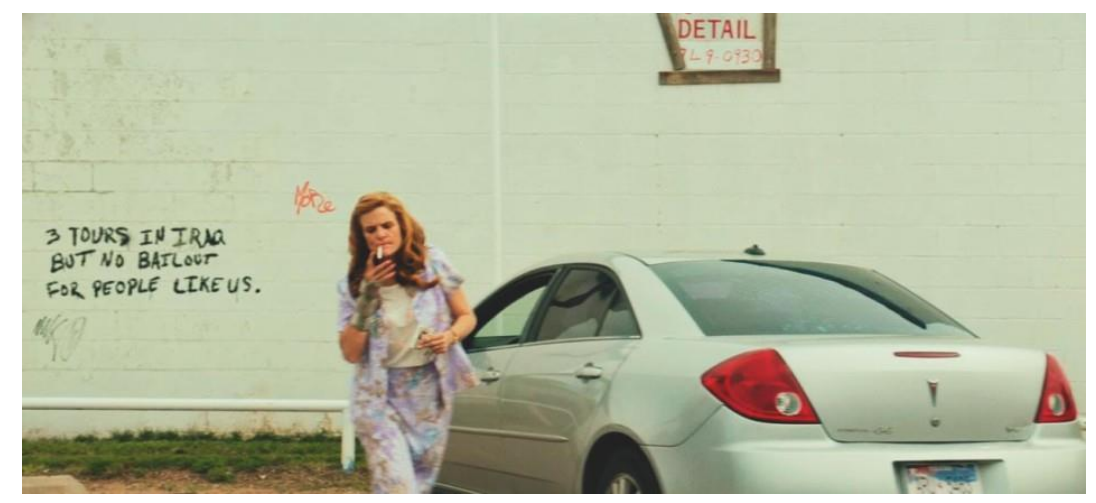

Figura 2: Fotograma de la película

\section{2. El espacio fronterizo}

La película se desarrolla en un espacio autóctono. La geografía rural del estado de Texas representa a la perfección el paisaje del western. Un paisaje intenso y cegador que aún no ha perdido su capacidad abrumadora. La vasta extensión de tierra lo rige todo. Como un personaje más, el espacio horizontal en el que se desarrollan los acontecimientos encubre una visión concreta del mundo. En palabras de Fernández-Santos, «una forma de existencia dramática de la naturaleza» (2007: 31). De este modo, a lo largo de todo el filme está presente un rigor atávico del que los personajes no pueden huir. Una llamada de la tierra que es a la vez limpia e inocente pero que encierra la violencia natural con la que tubo que enfrentarse el colono.

La pradera, el desierto, el espacio esencial del western, dibuja en la retina del espectador una imagen de horizontalidad que no es únicamente geográfica, sino que adquiere en la pantalla una inesperada vertiente moral: la imagen de una rectitud que se proclama inocente pero que no obstante participa en el debate sobre una oscura culpa (Fernández-Santos, 2007: 31).

Todo western se desarrolla en un espacio de frontera física o conceptual. Esta frontera, asociada a lo inhóspito e inhabitado, permite desarrollar el drama con la connivencia del paisaje. En Comanchería, la apelación constante a un paisaje agreste; climáticamente duro, presupone la forja de caracteres concretos en sus protagonistas. De este modo, los hermanos Toby y Tanner conviven con la frontera y deciden traspasarla (metafóricamente) como si estuvieran guiados por la hostilidad circundante.

La frontera a menudo sitúa a sus habitantes en la tesitura de elegir, de adoptar una opción a uno u otro lado. Es esa sensación espacial incómoda la que hace que los hermanos tomen la difícil decisión de caminar al otro lado de la ley. Un espacio que de forma abstracta está gobernado por sus propias normas (Fernández-Santos, 2007), que posibilitan, entre otras cosas, que todo un pueblo decida tomarse la justicia por su mano y perseguir, armas en ristre, a los atracadores hasta las afueras. Un espacio que deja de existir literalmente para transformarse en un marco reconocible en el que los acontecimientos se explican a través de una compleja lógica interna. Esto tiene su reflejo en comportamientos como el de la camarera de restaurante que, tras recibir una cuantiosa propina (200 
dólares) de manos de uno de los atracadores, se niega a entregársela al Ranger porque, a pesar de que supone una prueba para la investigación, es en realidad la única posibilidad de seguir pagando el alquiler.

Se podría afirmar, pues, que la tensión flota en el espacio del western. Que se promueve una cierta «violencia espacial». Y es que «el hombre de frontera siente rencor hacia un pasado que le ha conducido a un lugar sin futuro: vive por lo tanto sumergido en un presente absoluto» (FernándezSantos, 2007: 152). Y es el hermano mayor, Tanner, ex convicto y con un historial considerable de violencia a sus espaldas el que mejor encarna la esencia del hombre de frontera. Es más, Tanner verbaliza su sentir en una breve pero intensa conversación con un indio comanche en un casino:

TANNER: ¿Eres un comanche? ¡Los señores de las llanuras!

INDIO: Ya no somos señores de nada. ¿Sabes lo que significa comanche? Significa «enemigos para siempre».

TANNER: ¿Enemigos de quién?

INDIO: De todo el mundo.

TANNER: Entonces yo soy...

INDIO: ¿Un enemigo?

TANNER: No. Entonces soy un comanche.

Esta relación con el entorno tan definida se cristalizará en la declaración abierta de guerra que más adelante llevará a término el propio Tanner. Lo que Fernández-Santos denomina «inminencia de guerra» es la actitud permanente de guardia ante la hostilidad de un territorio que nunca se ha llegado a dominar del todo. Esto es, la sensación perpetua que tiene cada uno de los personajes de pérdida cotidiana en la lucha contra la naturaleza agresora. Tanner lo ha visto claro y apela una vez más a la violencia liberalizadora vehiculada a través del espacio salvaje para intentar una vez más (como ya lo hicieran sus antepasados), conquistar la realidad en la que habita.

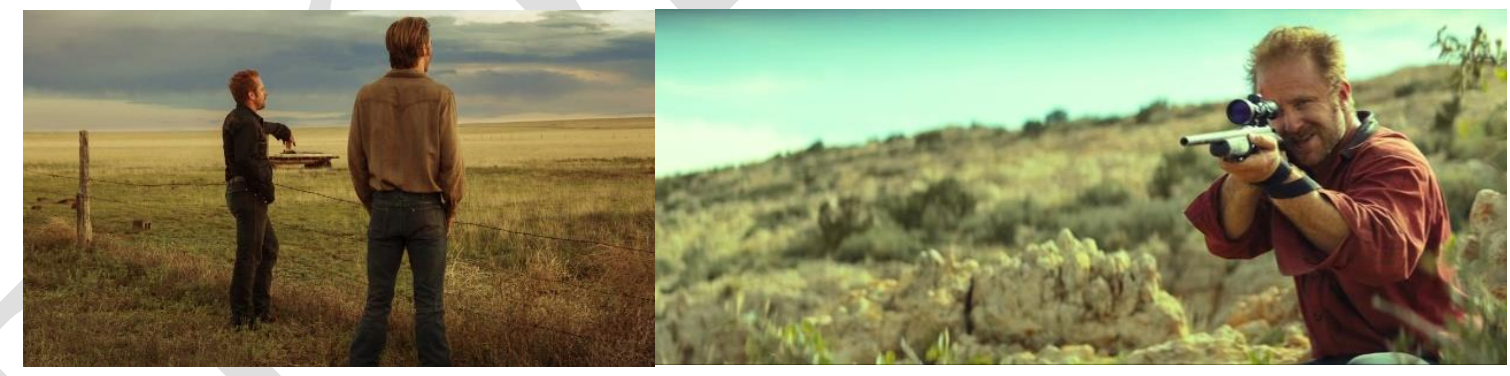

Figura 3: Fotogramas de la película.

\section{3. Los habitantes del western}

Los personajes que habitan este espacio singular son personajes estereotipados que, al igual que el género al que pertenecen, tienen la capacidad de ir mutando de matiz en matiz. Sin duda, el personaje que mejor se desenvuelve en este territorio hostil del que se viene hablando, es el pistolero. Entre lo vulgar y lo mítico, el pistolero es un hombre de moral dudosa que actúa por motivaciones estrictamente personales al margen de la ley -el outlaw-. Este personaje, a menudo identificado como «el malo» por 
el espectador, está cargado en el western de una potencia poética extraordinaria. El pistolero supone una oposición frontal al orden que establece la ley impuesta pero, al mismo tiempo, encierra en su idiosincrasia la franqueza cruel del tiempo mítico.

En Comanchería los pistoleros -los hermanos- se caracterizan por su coherencia franca; por lo que podría denominarse como «la conciencia del delito». Esto lleva a Toby y a Tanner a seleccionar para sus atracos aquellas sucursales bancarias de tamaño medio en las que no haya demasiadas personas y así evitar situaciones comprometidas. De igual modo, han trazado un plan en el que el dinero robado tendrá un límite máximo y, en la medida de lo posible, tratarán con respeto a las empleadas de banca (mayoritariamente mujeres).

Pero, al mismo tiempo, el pistolero es implacable. Peleará sin descanso para alcanzar sus objetivos de manera fría y, frecuentemente, es el portador de la muerte. En el filme dirigido por Mackenzie esta inercia está especialmente retratada: hay un punto claro de inflexión cuando Tanner asesina a sangre fría a un cliente de la sucursal en el transcurso de su último atraco. Este es el instante concreto en el que prevalece la esencia malvada del personaje estereotipado del pistolero para garantizar su supervivencia en esta tierra hostil. La grandeza de este personaje (casi heroico) es la aceptación sin concesiones de las consecuencias que se derivarán de sus acciones. Quizá sea esa coherencia sin matices la que convierte al pistolero en un personaje respetable:

El malo ejerce su maldad a cuerpo limpio; no es un hipócrita, no puede serlo; no se oculta, aunque su oficio es no ser reconocido allí donde desciende de su caballo. Es un ser totalmente contenido en su apariencia: jamás niega su maldad, sino que, por el contrario, la acepta con resignación estoica y es fiel a las consecuencias, incluidas las más atroces [...] es un hombre de una pieza, forjado de una vez por la naturaleza, con la coherencia exterior y la cohesión interior de un criminal (Fernández-Santos, 2007: 178).

Esto supone que el pistolero es un hombre de honor. No es un mero villano que actúa de forma irrespetuosa e incoherente. Al contrario, se muestra revestido de cierta legitimidad en su comportamiento. Es un hombre consciente de «las amenazas salvajes de su medio y las afronta con un signo de fatalidad en el gesto» (Fernández-Santos, 2007: 199).

Comanchería conserva de manera esencial esta tipología de personaje. El espectador capta perfectamente los matices que lo conforman y puede ver más allá de las acciones ilegítimas que llevan a cabo los dos hermanos. Se observa así cómo el neowestern que abordamos mantiene intactos los códigos westernianos en relación con la ambivalencia moral de unos personajes aparentemente simples que exceden las implicaciones éticas de las categorías de bien y mal.

No existe el western sin la idea de justicia. No es un principio dominador del orden social: es una «idea». Es decir, la justicia en este género cinematográfico se convierte en parte esencial de cada individuo; en una cuestión íntima y personal. De este modo, «cada hombre en el Oeste tiene su propia idea de justicia y, lo que es más inquietante, [...] la posibilidad de llevarla a la práctica» (SantosFernández, 2007: 216). Sin duda, este carácter subjetivo de la justicia es la base conceptual del principio de legítima defensa norteamericano tan conocido y discutido en las últimas décadas. Lo cierto es que la máxima de «matar para seguir viviendo» está presente de un modo inamovible en la concepción social del western. Más aún si se tiene en cuenta que alcanzar la paz social es una 
pretensión especialmente frágil en las coordenadas espacio-temporales del género. Más bien todo lo contrario: los habitantes de estas latitudes viven en un estado permanente de alerta. Han de prevenirse constantemente debido a la categoría de cotidianeidad que se le otorga al robo, la revancha o el asesinato.

En relación con lo señalado, solo un personaje con similar carga mítica a la del pistolero o forajido puede ser el encargado de velar por una cierta estabilidad en la convivencia: el sheriff o marshall. Esta figura, a menudo controvertida, representa un estado de transición entre el orden natural y el orden social. Entre la esencia humana más descarnada y la conveniencia perpetua de la convivencia ordenada. De este modo, por pertenecer a un tiempo de fundación mítica, el sheriff no actúa en representación de la ley; él es la ley: «En este mundo que recomienza su aventura, en donde de nuevo se comete el primer asesinato, donde es preciso definir el bien y el mal denominándoles "justo" e "injusto", "legal” e "ilegal”, el Marshall cumple la función de legislador bíblico. Es juez y guardián de la nueva ciudad (González Sánchez, 2012).

Comanchería asume de manera inequívoca el estereotipo del personaje, encarnado en el Ranger al que da vida en la pantalla Jeff Bridges. Este juez y guardián a punto de jubilarse, representa el modelo rudo, simple y sincero de sheriff cuya misión es la de castigar al delincuente.
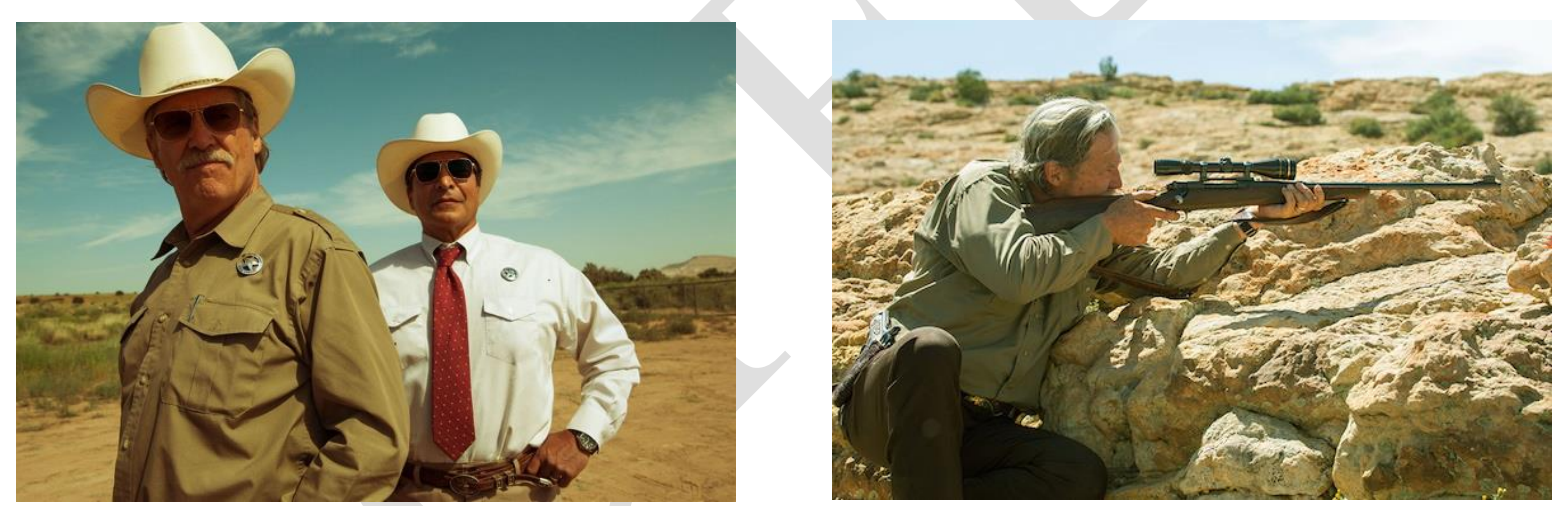

Figura 4: Fotogramas de la película.

Su carácter distante, su humor racista y un conocimiento profundo del comportamiento humano retratan a un personaje complejo. El Ranger es un animal en peligro de extinción. Representa los últimos vestigios de un modo de aplicar la justicia poco ortodoxo que consiste en dar caza al delincuente. Para ello, el olfato y la paciencia son condiciones indispensables que demuestra sobradamente a lo largo del filme.

Pero este sheriff también representa (de ahí la grandeza del personaje) la decrepitud propia de la extinción. Mackenzie lo reviste durante todo el metraje de una nostalgia poética que solo alcanzan los epígonos. Los que se saben fuera de un tiempo que ya no reconocen. 


\section{4. El tiempo de la usurpación}

El robo como delito histórico dentro del género del western encierra implicaciones interpretativas más profundas. Tanto los asaltos a diligencias o ferrocarriles (robos en movimiento) como los atracos a los bancos forman parte del imaginario de este género cinematográfico. «La exaltación de la usurpación» como la denomina Ángel Fernández-Santos significa elevar al lenguaje heroico un comportamiento prosaico (Fernández-Santos, 2007).

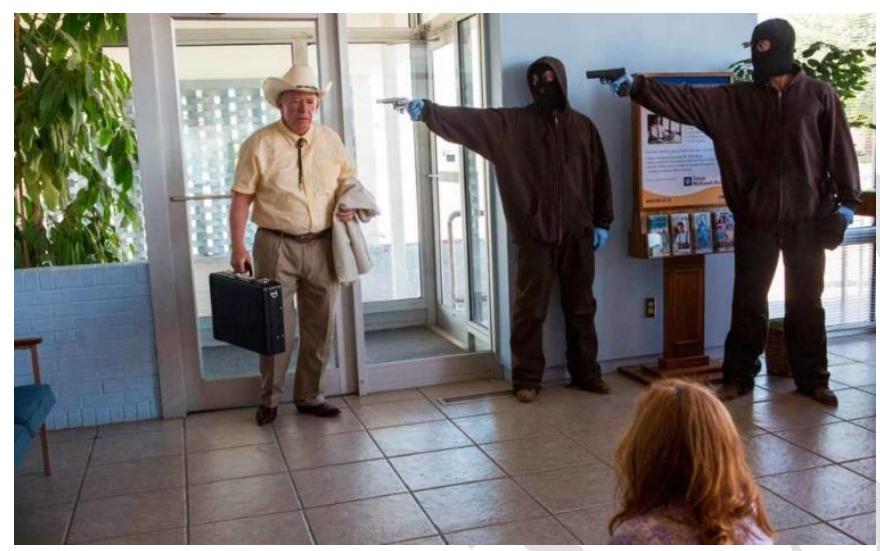

Figura 5: Fotograma de la película.

De este modo, lo que pudiera parecer un simple acto de rapiña pasa a considerarse por los códigos del western un atentado grave contra uno de los principios fundamentales en los que se basó la conquista del Oeste: la propiedad privada.

La mitificación de la propiedad privada tiene que ver con el carácter campesino de la conquista, en la que los granjeros y ganaderos convirtieron en realidad el mito bíblico de la Tierra Prometida. De este modo, cualquier atentado contra la propiedad privada es decodificado por el género como un atentado contra la idea fundacional de sociedad.

Una visión histórica que defiende la prevalencia de los valores capitalistas sobre los democráticos en la concepción de EE. UU. como país, y que estaría en consonancia con la representación westerniana de la propiedad es la defendida por el historiador Richard Hofstadter cuando afirma que los padres de la patria Americana eran:

Hombres de negocios, granjeros, inversionistas, especuladores, para los que el concepto de libertad no estaba ligado al de democracia, sino al de propiedad. [De ahí] que las tradiciones norteamericanas adolezcan de un marcado prejuicio en favor de una democracia basada más en la codicia que en la fraternidad (en Fernández-Santos).

Comanchería conserva intacta esa visión sobre la tierra. Mantener la propiedad es la única vía para conservar la dignidad; más aún, es la única forma de mantener vivo el mito de la refundación y, por tanto, volver a empezar de nuevo. Las motivaciones de los hermanos Toby y Tanner para atracar los bancos y ejercer así un tipo de violencia concreto, no solo son entendibles sino que desde la mirada del western son legítimas: en la escena final de la película, Toby verbaliza la idea básica de la que nace el american dream: «He sido pobre toda mi vida. También lo fueron mis padres y los padres de mis 
padres. Es como una enfermedad que pasa de generación en generación y acaba haciéndose crónica; infecta a todo el mundo. Pero no a mis hijos. Ya no. Esto ahora es de ellos».

Se establece en el filme, como herencia directa de la retórica westerniana, una identificación entre propiedad privada y violencia. Si bien es cierto que los términos en los que se vinculan no son los clásicos (la defensa a través de medios violentos de la propiedad ante agresiones externas), la violencia ejercida por los atracadores se salda con cuatro muertes. Robar el dinero de los bancos para conservar la propiedad privada y favorecer así que siga transmitiéndose de generación en generación se convierte por tradición en un casus belli. Este hecho, perfectamente convencional en los códigos del western, ha de considerarse en Comanchería un hecho excepcional que solo encuentra su explicación en el hallazgo de petróleo en esa propiedad privada. Por tanto, el filme de Mackenzie conjuga la tradición definida por la realidad histórica de la parcelación como origen de la propiedad privada durante la conquista del Oeste, y la defensa de la misma, con la vinculación de esa tierra a una identidad nacional que dota a su poseedor de un derecho consuetudinario heredado de sus antepasados y que está obligado a legar a sus descendientes. Cuando Toby, un pistolero alejado de sentimentalismos, afirma que sus hijos ya no van a padecer la enfermedad de la pobreza, cree realmente que les ampara el derecho primitivo de poseer la tierra que se pisa. Considera, por tanto, que han adquirido una responsabilidad legada por los primeros hombres que en la fundación mítica decidieron establecerse allí y defender su derecho divino a la posesión de ese territorio² ${ }^{2}$

\section{La poética de la ausencia: a modo de conclusión}

El concepto de neowestern define un fenómeno extremadamente interesante desde el punto de vista de la teoría cinematográfica. Este vocablo alude a películas que heredan de manera directa los códigos narrativos del western en un espacio y tiempo actuales, es decir, fuera de las coordenadas naturales del género. Se podría afirmar, por tanto, que el subgénero del neowestern refleja una poética ausente. Desde este punto de vista podrían entenderse los neowesterns como simulacros actuales del western clásico en los que ya no se elabora un discurso mítico sino que se reformulan las estructuras de ese discurso adaptándolas a un tiempo actual en contextos de crisis.

Si el western cumple una función mitologizadora de un pasado heroico ya perdido (SánchezNoriega, 2002), el neowestern toma ese hecho como punto de partida para derivar en un cine social marcado por el sentimiento de fracaso.

Películas como Los tres entierros de Melquiades Estrada (The Three Burials of Melquíades Estrada, Tommy Lee Jones, 2005), No es país para viejos (No Country for Old Men, Joel y Ethan Coen, 2007) o Comanchería son una manifestación de ese sentimiento de derrota. Los protagonistas de estas historias se han rendido ante la crueldad del paisaje. Son hombres vencidos por el «salvaje» Oeste. Ya solo confían, pues, en un golpe se suerte; en un error del destino que les haga vivir de nuevo la sensación de conquista. Los neowesterns son, en último término, la negación del western. Es decir,

\footnotetext{
${ }^{2}$ Esta idea está en el origen de la conquista del Oeste y explica en buena medida las atrocidades cometidas con los pueblos indígenas. Los primeros colonos lo llamaban «destino manifiesto».
} 
la constatación del fracaso de su mitología. Este hecho grave está relacionado para algunos críticos con el final de la hazaña colectiva del viaje. Esto es, con la transformación de la utopía fundacional (representada visualmente por las hileras de caravanas) a la parcelación y defensa de la tierra, cuya metáfora perfecta sería el vaquero armado en el porche de su casa.

Si se acepta la premisa arriba enunciada, el protagonista del neowestern ha perdido su impronta de héroe épico para transformarse en un héroe trágico (Fernández-Santos, 2007). Se ha convertido en un personaje centrado en ordenar su vida cotidiana -ordinaria- perdiendo la épica de la conquista. Por otra parte, adopta un carácter trágico que deviene de su contexto natural de marginalidad en la mayor parte de los casos (Simões Rodrigues, 2016). Además, en el pistolero del neowestern se subraya más, si cabe, la idea clásica del fatum por la que el destino aciago del héroe no le pertenece. Al contrario, es víctima de sus circunstancias.

En la película dirigida por Mackenzie, Toby, pero sobre todo Tanner, representan a dúo el papel del héroe trágico. Golpeados por la vida heredada de sus antepasados, resignados y rebelados solo pueden asumir su condición de marginados e intentar romper su destino. Como todo héroe trágico, los hermanos sufren un ascenso y una caída, esta última motivada en buena parte por la soberbia (hybris) que no les augura un final victorioso, especialmente a Tanner.

«El relato del desmoronamiento es uno de los rasgos medulares del western» (Fernández-Santos, 2007: 129), como también lo es del neowestern. En estos westerns modernos, además de la crónica de una mitología deficitaria (aunque totalmente representativa), se narra la constatación de un fracaso: el de la utopía rural.

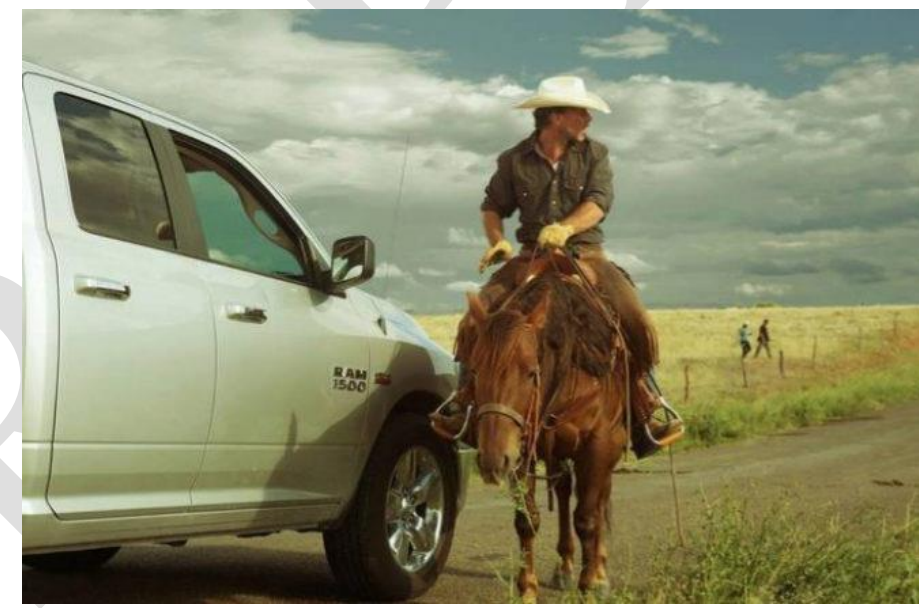

Figura 6: Fotograma de la película.

En origen, agricultores, ganaderos y vaqueros - cowboys- no fueron capaces de llevar a término una realidad social estable. Enfrentados por la tierra, los pastos o el agua erosionaron generación tras generación la armonía civil. El neowestern también es testigo de ese valor perdido y presenta la ruralidad como un lugar de conflictos en el que solo los que no son conscientes de que el proyecto ha fracasado siguen pretendiendo que la figura del cowboy prevalezca. Por tanto, la oposición campo- 
cuidad en este subgénero cinematográfico refleja dos formas de agrupación (y en consecuencia de propiedad, economía y estructura social) que ya no conviven porque la segunda ha fagocitado a la primera. El vaquero no entiende de especulaciones, mercados o acciones, más bien intenta una rentabilidad inmediata ya extinguida que contribuye a reforzar la mitología trágica del neowestern.

El valor de este tipo de filmes, y el de Comanchería en particular, estriba en su valor revisionista. Esto supone una labor titánica ya que lo que se somete a revisión es nada más y nada menos que la mitología de una colectividad.

El cine, al igual que forjó los elementos identitarios sobre los que se sustenta buena parte de la idea de Nación Americana, tiene ahora potestad para reinterpretar esos mismos códigos y ajustarlos con pretendida justicia social a la realidad actual.

\section{Referencias bibliográficas}

Astre, G. A. y HoArau, P. (1998): El universo del western. Madrid, Fundamentos.

BALló J. y PÉREZ, X. (1997): La semilla inmortal. Barcelona, Anagrama, 2007.

BAZIN, A. (1990): ¿Qué es el cine? Madrid, Rialp.

FERnÁNDEZ SAntos, A. (2007): Más allá del Oeste. Barcelona, Debate.

GONZÁlEZ SÁNCHEZ, F. (2012): «Héroes, antihéroes y villanos en el cine western español», Razón y Palabra, 78.

SÁncheZ NoriegA, J. L. (2002): Historia del cine. Teoría y géneros cinematográficos, fotografía y televisión. Barcelona, Alianza Editorial, 2006.

SÁNCHEZ VIDAL, A. (1997): Historia del cine. Madrid, Historia 16.

SiMÕES RoDRIGUES, N. (2016): «Tragedia griega y western americano: estudio de cuatro casos», Habis, 47, pp. 307-323.

Voces FernándeZ, J. (2013): «Séneca en el lejano Oeste: Fedra West (Joaquín L. Romero Marchent, 1968) o la relectura de una tragedia griega» en J. A. PÉREZ BowIE, ed., La noche se mueve: adaptación en el cine del tardofranquismo. Madrid, Libros de la Catarata. 